\title{
Assessment of resource-use strategy of some common woody plant species grown under semiarid climatic condition of Quetta Balochistan-Pakistan
}

\author{
Mahjabeen Jaffar ${ }^{1 *}$, Saadullah Khan Leghari ${ }^{1}$, Muhammad Anwar Khan \\ Panazai $^{2}$ and Manzoor Iqbal Khattak ${ }^{3}$ \\ 1. Department of Botany, University of Balochistan, Quetta-Pakistan \\ 2. Institute of Biochemistry, University of Balochistan, Quetta-Pakistan \\ 3. Department of Chemistry University of Balochistan, Quetta-Pakistan \\ *Corresponding author's email: jaffarmahjabeen46@gmail.com \\ Citation \\ Mahjabeen Jaffar, Saadullah Khan Leghari, Muhammad Anwar Khan Panazai and Manzoor Iqbal Khattak. \\ Assessment of resource-use strategy of some common woody plant species grown under semiarid climatic condition \\ of Quetta Balochistan-Pakistan. Pure and Applied Biology. Vol. 8, Issue 2, pp1830-1840. \\ http://dx.doi.org/10.19045/bspab.2019.80127
}

\begin{tabular}{llll}
\hline \hline Received: 22/04/2019 & Revised: 24/06/2019 & Accepted: 27/06/2019 & Online First: 29/06/2019 \\
\hline \hline
\end{tabular}

\section{Abstract}

The aim of this study was to evaluate the resource use strategy of some woody plants in semi-arid climatic condition of Quetta, Balochistan Pakistan. The plant sample were collected from eleven selected different woody plant species namely; Fraxinus xanthoxyloides, Robinia pseudoacacia, Ficus carica, Morus alba, Morus nigra, Ailanthus altissima, Melia azedarach, Pinus halepensis. Malus domestica, Prunus armeniaca and Tamarix sp. during three seasons spring, summer and autumn, in 2017-18. The resources-use strategy of the selected plant species was determined by commonly used indicators such as Leaf Relative Water Content (LRWC), Leaf Dry Matter Content (LDMC) and Live Fine Fuel Moisture Content (LFFMC). Data regarding annual average RWC, LDMC and LFFMC in all the investigated plant was found in ranged between 25.12-73.89\%, $0.21-0.40 \mathrm{mg} / \mathrm{g}$ and $58.0-221.0 \mathrm{mg} / \mathrm{g}$, respectively. The maximum annual average RWC, LDMC and LFFMC was reported in Ficus carica, Pinus halepensis and Melia azedarach, while the minimum was found in Alianthus altissima, Fraxinus xanthoxyloides and Alianthus altissima, respectively. Among seasons; the highest RWC was found during spring which followed by summer and minimum was originated in autumn season. The higher LDMC was recorded in autumn season as compared to summer and spring, suggesting a more efficient conservation of nutrients and the maximum LFFM contents were found in autumn followed by summer and lowest was in spring.

Keywords: Balochistan; Plant species; Relative water content; Live fine fuel moisture content; Dry matter content 


\section{Introduction}

The study of RWC, LDMC and LFFM dynamics are important to understand the water use/resources use efficiency, cause of the flammability of flora and to assess fluctuations in measured wetness inside the background of variations both in real water content of leaf and in dry weight of leaf. The amount of moisture contents in the leaves of wild terrestrial plants change with the varying season. The moisture contents and growth behavior of the plant not usually increase or decrease smoothly, it mostly depend on the climatic condition of the local area. There are many reasons behind these unevenness, which contains the changing demand in food manufacturing, weather alterations and variability in soil moisture [1]. However, within the individual leaf, moisture retained within a manageable limitations during the developing season, because the plant leaves have capability of opening or closing the stomata through which it regulate the rate of transpiration in the atmosphere.

Larcher [2] and Teulat et al. [3] stated that the Leaf relative water content estimates plants water status. The decrease in leaf RWC lead to reduce in the rate of photosynthesis and conductance of stomata [4]. Ogunkunle et al. [5] observed that RWC varied considerably across the sites. Garnier et al. [6] reported that the Leaf dry matter content (LDMC) is the main indicator of resource use ability of a plant. This feature is linked with the leaf lifecycle and it is also involved in a major interchange between immediate production of biomass and an effective conservation of the nutrients [7-9]. Garnier et al. [10] reported that the relative water content, leaf dry matter content (it is a proportion of the leaf dry mass to fresh mass) and live fine fuel are the vital plants ecological traits because they are related to several critical phases of plants development and existence. So the living fuel moisture content is utilized in numerous fire model systems and it can be calculated through leaf moisture (LM) and live fine fuel moisture (LFFM) contents from the leaves $[11,12]$. It has been also used in defining the aspects of explosion and scattering of the fire [13].

Basically this investigation was conducted to develop a method for assessing the resource use strategy of plants under semi-arid climatic condition and environmental variability as well as identify production pressures which are controlled by different plant leaf parameters such as relative water content, dry matter content and live fine fuel moisture content.

The main objective of the study was to assess the resource-use strategy of some common woody plant species growing in semiarid climatic condition of Quetta, Balochistan through relative water content (RWC), leaf dry matter content (LDMC) and live fine fuel moisture (LFFM) contents and their seasonal variation.

\section{Materials and methods}

Five replicate leaf samples from eleven different woody plants species (Figure 1), were collected from Quetta and its surrounding during spring, summer and autumn season. Three leaf variables such as leaf relative water content (RWC), leaf dry matter content (LDMC) and live fine fuel moisture (LFFM) contents were measured from selected plant leaves throughout the study period. Leaf samples were taken from well grown plants and from that portion of the canopy subjected to indirect daylight during sampling period. The fully expended and free of pathogen leaves with petioles were detached from the plant stems as the method used by Garnier et al. [10]. The number and weight of the sampling leaf from each individuals were different according to their size and shape. The samples were together between 11AM to 2PM as the method used by Leghari et al. [1]. 


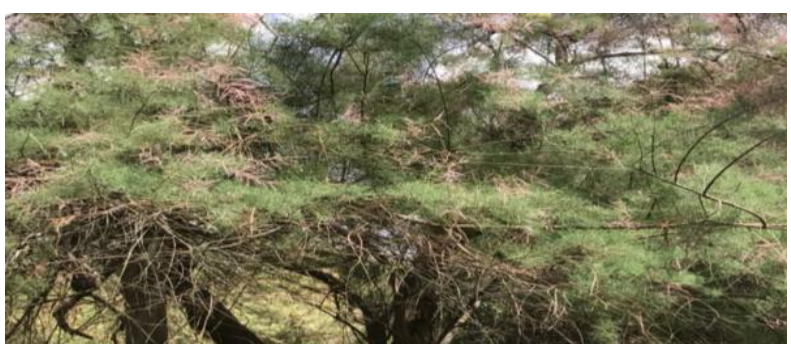

Tamarix sp

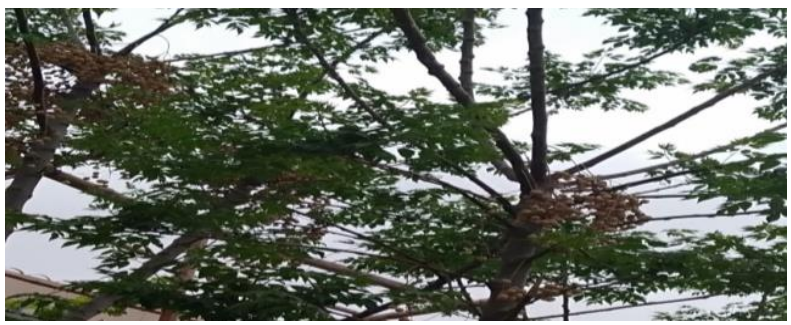

Melia azedarach

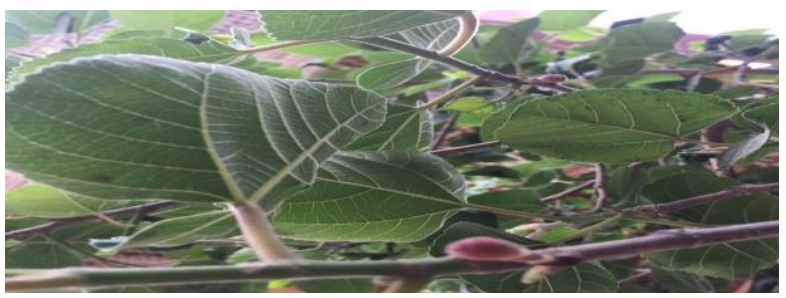

Ficus carica

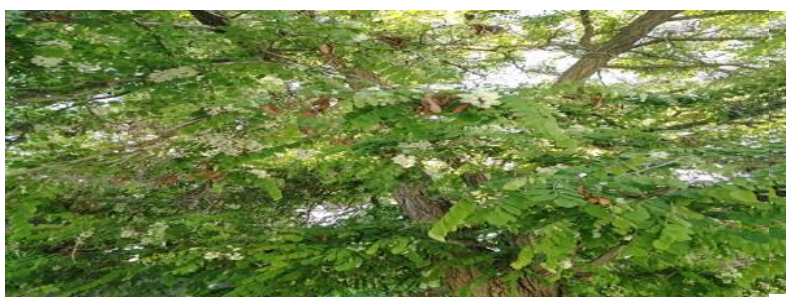

Robinia pseudoacacia

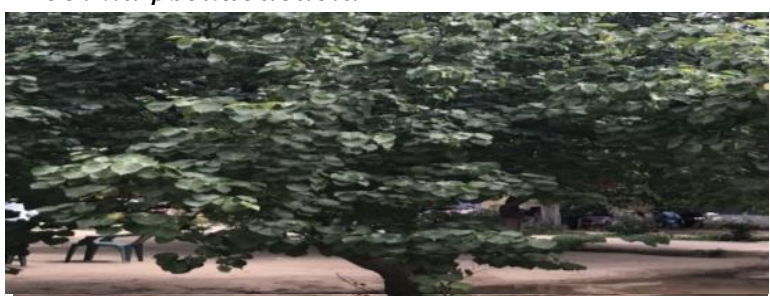

Prunus armeniaca

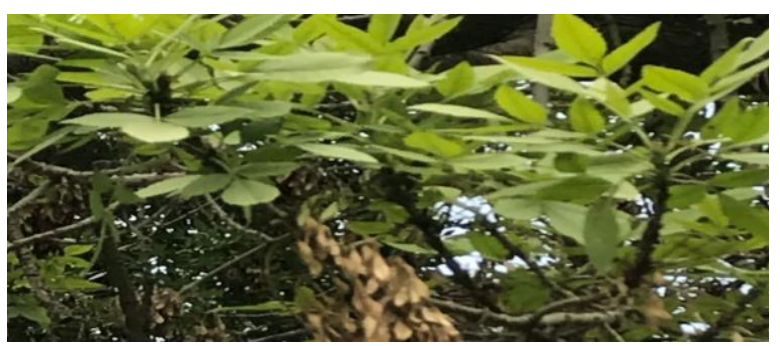

Fraxinus xanthoxyloides

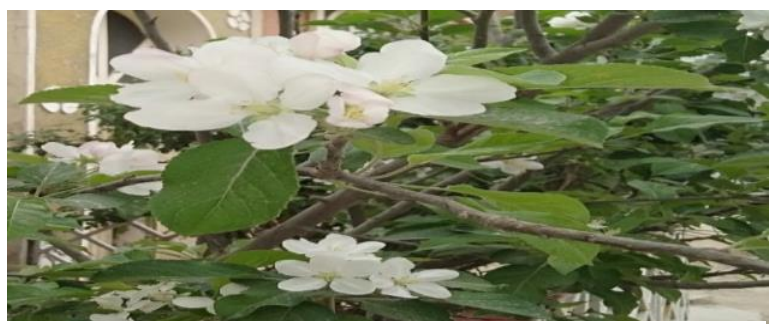

Malus domestica

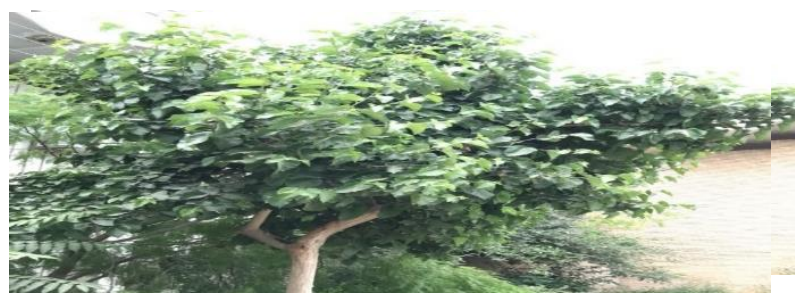

Morus nigra

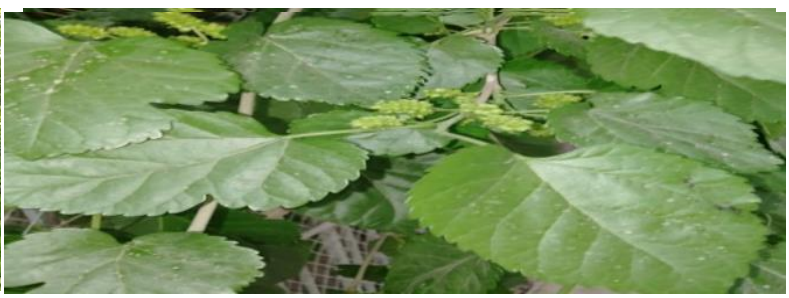

Morus alba

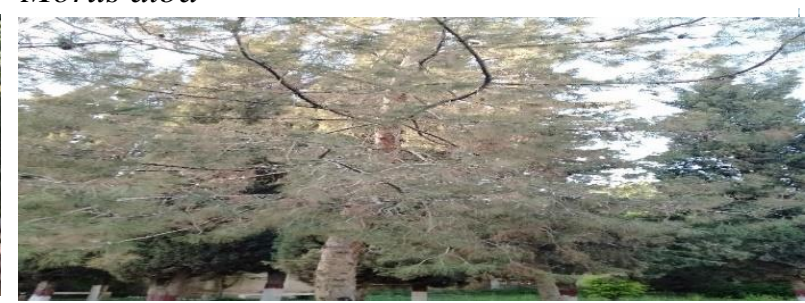

Pinus halepensis

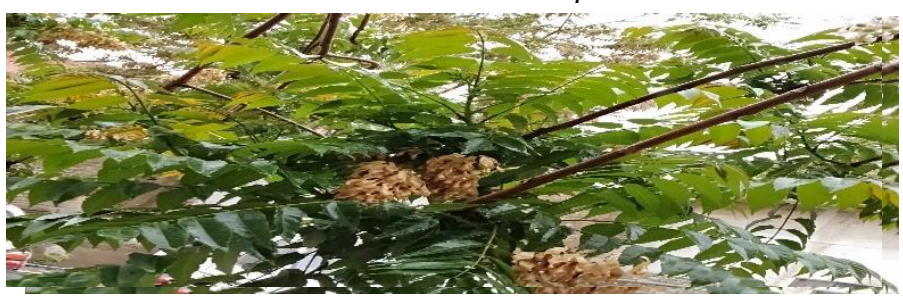

Ailanthus altissima

Figure 1. Eleven woody plant species of Quetta Balochistan selected for study 


\section{Measurement of Relative water content (RWC)}

RWC was determined by the methods as used by Leghari et al. [1] and Munne-Bosh and Pinellas [14]. Leaves samples from the selected plant species were brought to laboratory of Botany Department University of Balochistan, Quetta for different further process. Fresh weight of the sample leaves were determined by using electrical balance and then they were kept inside the plastic jars filled with water for saturation. A separate plastic jars full of water were used for each individual leaf sample and the sample was kept in jar for 6-9hrs [15]. After the saturation, turgid weight of the leaves were determined. To reduce the loss of water these plastic jars were conserved in ice-box condition. So as to get saturated weight of the leaves they were weighed outside the jar with precision of $0.01 \mathrm{~g}$. Finally, they were dehydrated in oven for $48 \mathrm{hrs}$ at $70{ }^{\circ} \mathrm{C}$ and weighed.

The RWC (\%) was determined by the following formula:

$\mathrm{RWC}=(\mathrm{Mf}-\mathrm{Md}) /(\mathrm{Mt}-\mathrm{Md}) \times 100$

Where Mf is a fresh mass of leaf, Mt is a turgid mass of leaf after rehydrating the leaves and Md is a dry mass after being oven dried. LDMC and LFFM were achieved with the same process as of RWC.

\section{Leaf dry matter content (LDMC) and live fine fuel moisture (LFFM)}

For LDMC and LFFM determination the leaves samples from selected eleven plant species were collected individually for each parameter. These leaves sample were closed in airtight plastic bags and kept in ice-box condition so the loss of water during journey from the field to laboratory remains within the plastic bag. Then they were weighed. Then the leaf samples were dehydrated in an oven for $48 \mathrm{hrs}$ at $70{ }^{\circ} \mathrm{C}$ and again weighed (f.wt and d.wt) with electrical balance by the accuracy of $0.01 \mathrm{~g}$. The LDMC and LFFM $\left(\mathrm{mg} \mathrm{g}^{-1}\right)$ were calculated by using following formula:

$\mathrm{LDMC}=\mathrm{Md} / \mathrm{Mt}$

LDMC is the quantity of the leaf matter content without water which is associated with the mass of the leaf with maximum content of water.

$\mathrm{LFFM}=[(\mathrm{Mf}-\mathrm{Md}) / \mathrm{Md}] \times 100$

LFFM indicates the quantities of the water in leaves under fields' environment in relative to its dry mass.

\section{Statistical analyses of the Data}

The dependent variables (RWC, LDMC and LFFMC) of the leaf samples were statistically analyzed and each value is mean of three replicates. The differences between the means were tested by using repeatedmeasures analyses of variance (ANOVAs) through SPSS software program version 16.

\section{Results and discussion}

The consequences of present study highlight the significance of periodical RWC, leaf dry matter contents variations and LFFM differences in 11 woody plant species grown in semi-arid climatic condition of Quetta Baluchistan Province of Pakistan. The current investigation also establishes that the plant species with different climatic condition showed diverse conduct in the expression of periodic scarcity once likened with seeders. However the region with semiarid type of climate, the whole plant species are expectable to bear summer drought. So, plant species exhibited dissimilar useful properties inside the ecosystem [16].

Relative water contents during spring, summer and autumn were found in ranged between 33.21-86.99\%, 24.55-71.83\% and $17.60-62.86 \%$ respectively. The highest leaf RWC was recorded for Ficus carica and lowest for Ailanthus altissima in all the three season. Among season the highest RWC was noted in spring which followed by summer and lowest was found in autumn season (Table 1). The highest RWC in spring season 
was also reported by Leghari et al. [1] in Pinus halepensis Miller., Eucalyptus tereticornis L. and Elaeagnus angustifolia L. The reduction in leaf moisture contents of the plant species during spring to autumn is not same, however a rough series of up and down in water contents is noted. These fluctuations might be due to many factors, such as differences in weather, disparities in obtainable soil moisture and episodic variations in food formation requirements. Inside the detached foliage, though, wetness is sustained within acceptable bounds throughout the rising period by aptitude of the foliage to opening and closing of the stomata and therefore controls the rate of transpiration in the air [1]. Leaf moisture contents might be change in the sequence of the day. In current study the statistical analysis indicated that out of 11 plant species 7 species (Ficus carica, Morus alba, Morus nigra, Ailanthus altissima, Tamarix sp, Robinia pseudoacacia, Melia azedarach) showed highly significant variation between different seasons, three other species (Fraxinus xanthoxyloides, Malus domestica, Prunus armeniaca) were found with significant variation and remaining one (Pinus halepensis) displayed slightly significant at $\mathrm{P}<0.05$ significant level. Statistical investigation also indicated that all the examined plant species were found highly

\section{Table 1. Relative water content in 11 woody plants species of Quetta Balochistan}

\begin{tabular}{|c|c|c|c|c|}
\hline \multirow{2}{*}{ Plants Species } & \multicolumn{3}{|c|}{ RWC } & \multirow{2}{*}{$\begin{array}{l}\text { Statistica } \\
\text { variation }\end{array}$} \\
\hline & Spring & Summer & Autumn & \\
\hline Fraxinus xanthoxyloides & 39.56 & 35.26 & 30.96 & $* *$ \\
\hline Ficus carica & 86.99 & 71.83 & 62.86 & $* * *$ \\
\hline Morus alba & 71.95 & 60.09 & 54.70 & $* * *$ \\
\hline Morus nigra & 70.13 & 63.98 & 55.34 & $* * *$ \\
\hline Ailanthus altissima & 33.21 & 24.55 & 17.60 & $* * *$ \\
\hline Pinus halepensis & 69.04 & 52.86 & 50.33 & $*$ \\
\hline Malus domestica & 61.60 & 56.71 & 52.88 & $* *$ \\
\hline Prunus armeniaca & 58.30 & 47.71 & 43.35 & $* *$ \\
\hline Tamarix sp & 72.83 & 29.96 & 26.29 & $* * *$ \\
\hline Robinia pseudoacacia & 62.02 & 57.32 & 47.31 & $* * *$ \\
\hline Melia azedarach & 76.44 & 64.04 & 58.01 & $* * *$ \\
\hline Pvalue & 0.002 & 0.000 & 0.000 & \\
\hline
\end{tabular}

Each mean value is the replicate of five readings, $*=$ slightly significant, $* *=$ significant, $* * *=$ highly significant and Ns $=$ nonsignificant significant different with respect to their leaf $\mathrm{RWC}$ at $\mathrm{P}<0.05$ significant level during three seasons (Table 1). Calculated annual mean value of leaf RWC in examined plant species were found in ranged 25.12-73.89\% (Figure 2). Highest annual average RWC was recorded from the leaves of Ficus carica and lowest was found in Ailanthus altissima leaves. Observation recorded by Leghari et al. [1] was also in agreement with these results. The height and feature mark, native micro-climate, produce reginal variations in periodical developments of several plant species. For example in mountainous landscape, the southern introductions and lower elevations support the earlier start of the growing season. Generally the moisture contents in newly developed leaves found highest at emerging time. Alike opinion was also stated by Saura-Mas and Lloret [17], who found that diverse plants species had different RWC by highest variations among season to season and specie to specie. They also noted that the RWC was meaningfully great in steady plant species than that of seeder species. The higher water content was also reported in A. indica in spring season by Paulsamy et al. [18]. Earlier studies also link the seasonal subtleties of RWC, LFMC, LDM contents in different plant species in different environments $[1,17,19,20]$. 


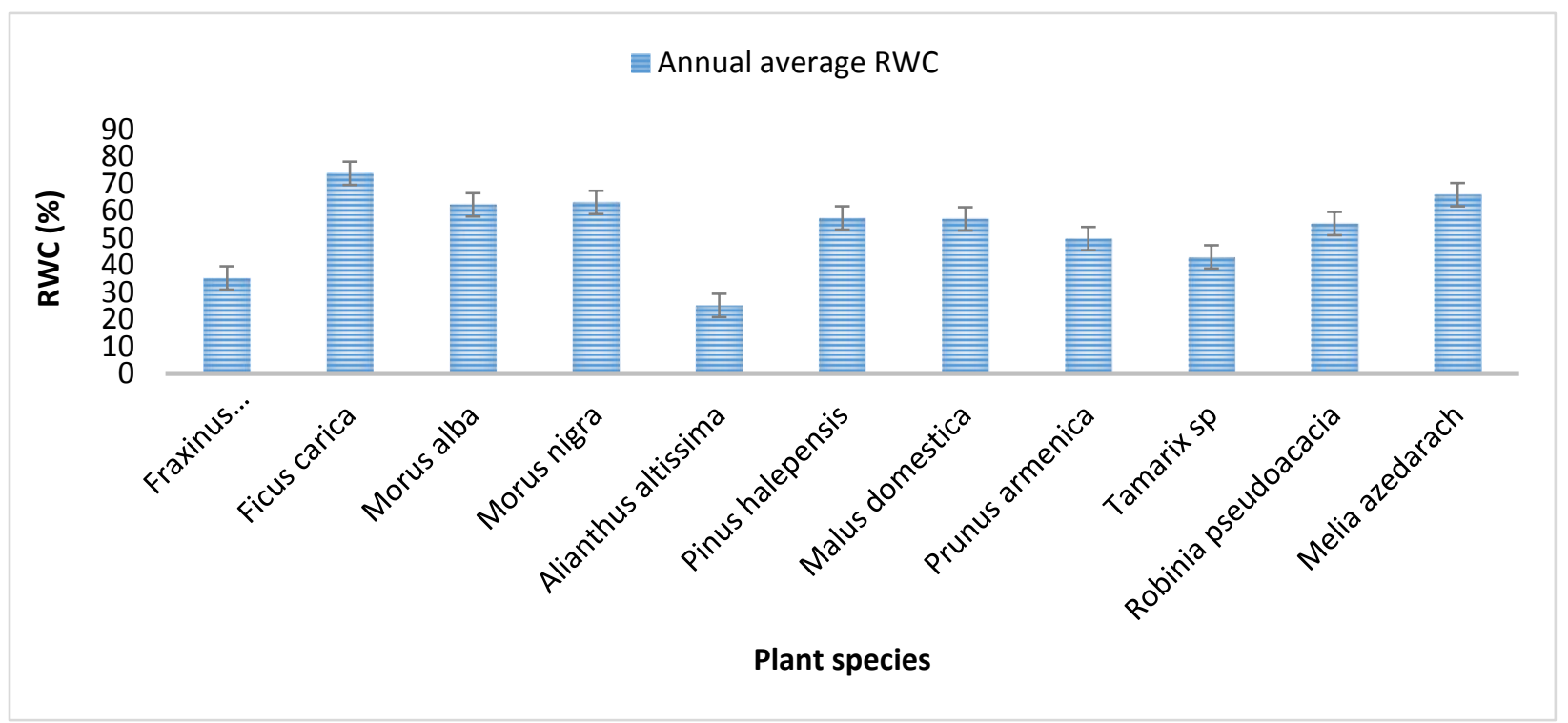

Figure 2. Annual average RWC in different 11 woody plant species of Quetta Balochistan

Leaf dry matter contents in examined plant species were found in ranged between 0.20 $0.39,0.22-0.42$ and $0.23-0.47 \mathrm{mg} / \mathrm{g}$ during spring, summer and autumn season respectively. Among plants the highest leaf dry matter contents was recorded in Pinus halepensis and lowest Fraxinus xanthoxyloides during all the three season. Statistical study designated that between different seasons the 3 plant species (Pinus halepensis, Malus domestica, Tamarix sp) showed significant variation, other three species (Ficus carica, Ailanthus altissima, Prunus armeniaca) exhibited only slightly significant and remaining 5 species (Fraxinus xanthoxyloides, Morus alba, Morus nigra, Robinia pseudoacacia, Melia azedarach) were found non-significant at $\mathrm{P}<0.05$ significant level. Significant test also indicated that in between examined plant species there was slightly to highly significant variation in their leaf DMC during all the seasons (Table 2). Intended annual average value of leaf DMC in 11 examined plant species were originated in ranged 0.21$0.40 \mathrm{mg} / \mathrm{g}$. The highest annual average DMC was noted from the leaves of Pinus halepensis and lowest was found in Fraxinus xanthoxyloides leaves (Figure 3). During different seasons the highest DMC was recorded in autumn which followed by summer and lowest was found in spring (Table 2). Variation in DMC during different seasons and in different plant species were also noted by other researchers $[1,17,19$, 20]. Significant differences in leaf dry matter contents were also noted by Saura-Mas and Lloret [17] between two seasons, the highest absorption was originated during autumn contrast to the summer season. Leghari et al. [1], during the investigation of leaf relative water, dry matter and live fine fuel moisture contents in some common plant species of Quetta, Balochistan during different season was found variation. They found lowest LDMC during spring and highest in autumn. These differences may be due to leaf age as the age increase the deposition of dry matter also became enhance. According to Garnier et al. [6], the leaf dry mater contents is a factor that does not differ very much among periods, meanwhile this factor depend on the dry mass of leaf and the extreme water that can be stored. Former researcher also recorded that unlike species rising in the 
same climatic conditions showed differences

in their LDM contents $[21,22]$.

Table 2. Leaf dry matter content (LDMC) $(\mathrm{mg} / \mathrm{g})$ in 11 woody plant species of Quetta Balochistan

\begin{tabular}{|c|c|c|c|c|}
\hline \multirow{2}{*}{ Plants Species } & \multicolumn{3}{|c|}{ LDMC } & \multirow{2}{*}{$\begin{array}{l}\text { Statistical } \\
\text { variation }\end{array}$} \\
\hline & Spring & Summer & Autumn & \\
\hline Fraxinus xanthoxyloides & 0.20 & 0.22 & 0.23 & $\mathrm{Ns}$ \\
\hline Ficus carica & 0.28 & 0.31 & 0.36 & $*$ \\
\hline Morus alba & 0.27 & 0.28 & 0.31 & Ns \\
\hline Morus nigra & 0.32 & 0.32 & 0.33 & Ns \\
\hline Ailanthus altissima & 0.27 & 0.29 & 0.30 & $*$ \\
\hline Pinus halepensis & 0.39 & 0.42 & 0.47 & $* *$ \\
\hline Malus domestica & 0.25 & 0.29 & 0.31 & $* *$ \\
\hline Prunus armeniaca & 0.24 & 0.26 & 0.27 & $*$ \\
\hline Tamarix $s p$ & 0.22 & 0.23 & 0.26 & $* *$ \\
\hline Robinia pseudoacacia & 0.26 & 0.27 & 0.28 & Ns \\
\hline Melia azedarach & 0.22 & 0.23 & 0.24 & Ns \\
\hline$P$ value & 0.031 & 0.041 & 0.017 & \\
\hline
\end{tabular}

Each mean value is the replicate of five readings, $\pm=$ standard deviation $*=$ slightly significant, $* *=$ significant, $* * *$ $=$ highly significant and Ns = non-significant

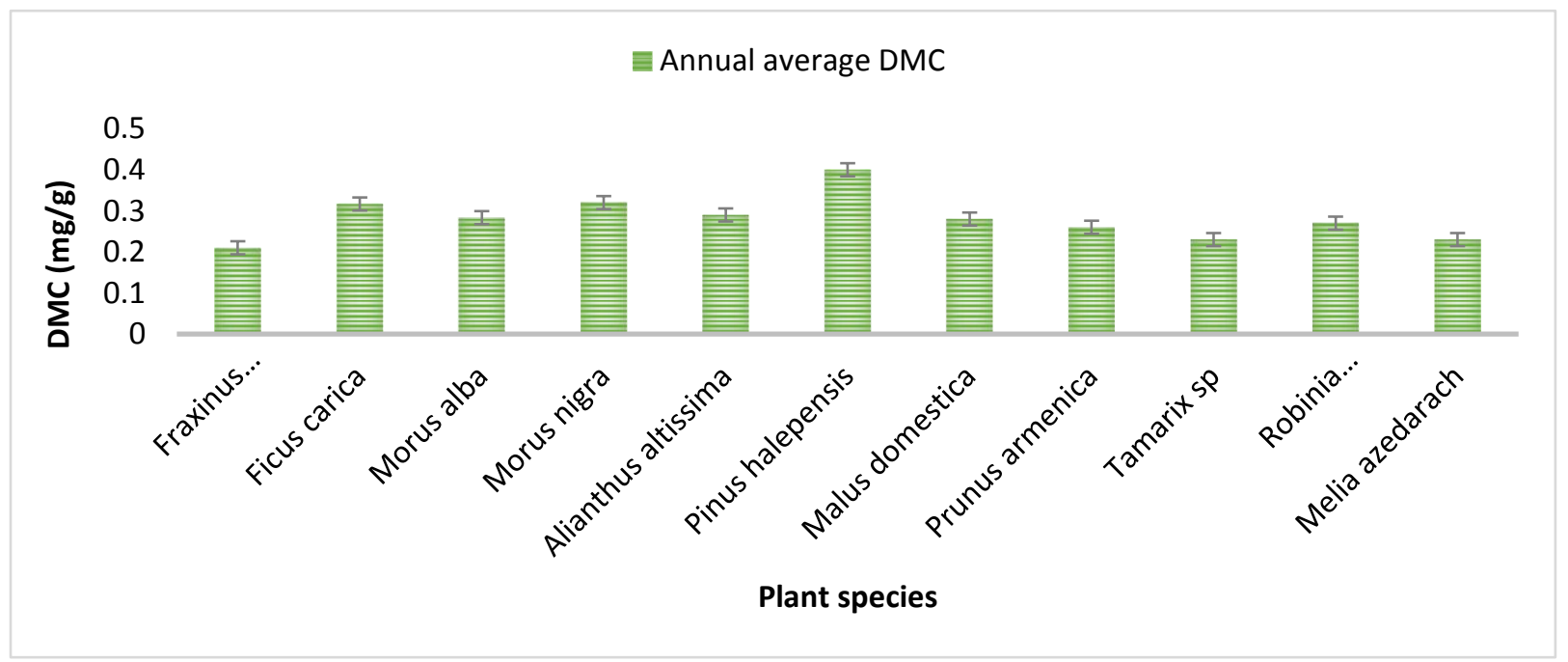

Figure 3. Annual average LDMC in different 11 woody plant species of Quetta Balochistan

Live fine fuel moisture contents has been documented as a significant cause of the flammability of flora. So, the measurement of LFFM indicated the capacity of any forest how much it can caught the fire. The entire Live fine fuel moisture (LFFM) during three season (spring, summer and autumn) were found in ranged between 47 - 189, 57- 218 and $68-256 \%$, respectively. Among all investigated plant species the highest LFFM contents was recorded in Melia azedarach and lowest in Ailanthus altissima during all three season (Figure 4). Statistical study designated that 6 plant species including Fraxinus xanthoxyloides, Pinus halepensis, Melus domestica, Prunus armeniaca, Robinia pseudoacacia, Melia azedarach, showed highly significant variation between different seasons, other three species (Ficus carica, Morus nigra, Tamarix sp) displayed 
significant and remaining two (Morus alba, Ailanthus altissima) were found slightly significant at $\mathrm{P}<0.05$ significant level, when it was compared between the season. Statistical analysis also indicated that all the examined plant species showed highly significant variation in their live fine fuel moisture, during spring, summer and autumn seasons (Table 3). Deliberated annual average LFFM in 11 inspected plant species were recorded in fluctuation between; 58 $221 \%$. The highest annual average LFFM was found in leaves of Melia azedarach and lowest in Ailanthus altissima. Variations in LFFMC from species to species and from season to season was also noted by Leghari $e t$ al. [1] under same ecological condition. Present data highlight the significance of periodical leaf dry weight variations and strain the required to assess fluctuations in measured wetness inside the background of variations both in the real water content of the leaf and in the dry matter content of the leaf. Moreover, they also highlighted that the carbon and water cycles of plants are directly influenced by LFFM contents. Earlier research has tried to link the periodical changing aspects of LFFMC to alterations in climatological circumstances, such as those are showed through several scarcity catalogs [23- 27]. Pellizzaro et al. [27] reported solid associations among LFFMC and drought indices for few Mediterranean bush species in the seasons of water strain, but then over poor relationships as deficiency pressure was reassured. Similar observation was also reported by Dimitrakopoulos and Bemmerzouk [26], they found that even though drought index strictly match the MC of herbaceous plant species and poorly correlated with leaf moisture contents of deep rooted plants such as $P$. brutia trees. Nelson [28] stated that the variation in total mass of water would be most linked to the water cycle of the tree and can be directly related to the soil, vegetation and atmospheric conditions. This is controlled by all the factors which directive the rate of water uptake from the soil, transport to the leaves and loss by the stomata. Further that Running [29] found a strong relation between leaf water potential and RWC in P. contorta. In dead fuel the dry weight is relatively determined and only changes gradually as a results of Decay [20]. Therefore, dead fuels moisture trail, fuels water weights differences control the direct diffusion and capillary movement of water into and out of fuels $[30,31]$. The false idea was set that live fuel performed equally and that first water weight diverse over time. Nevertheless, both dry weight of live fuel and water weight variations diurnally [32-36]. 


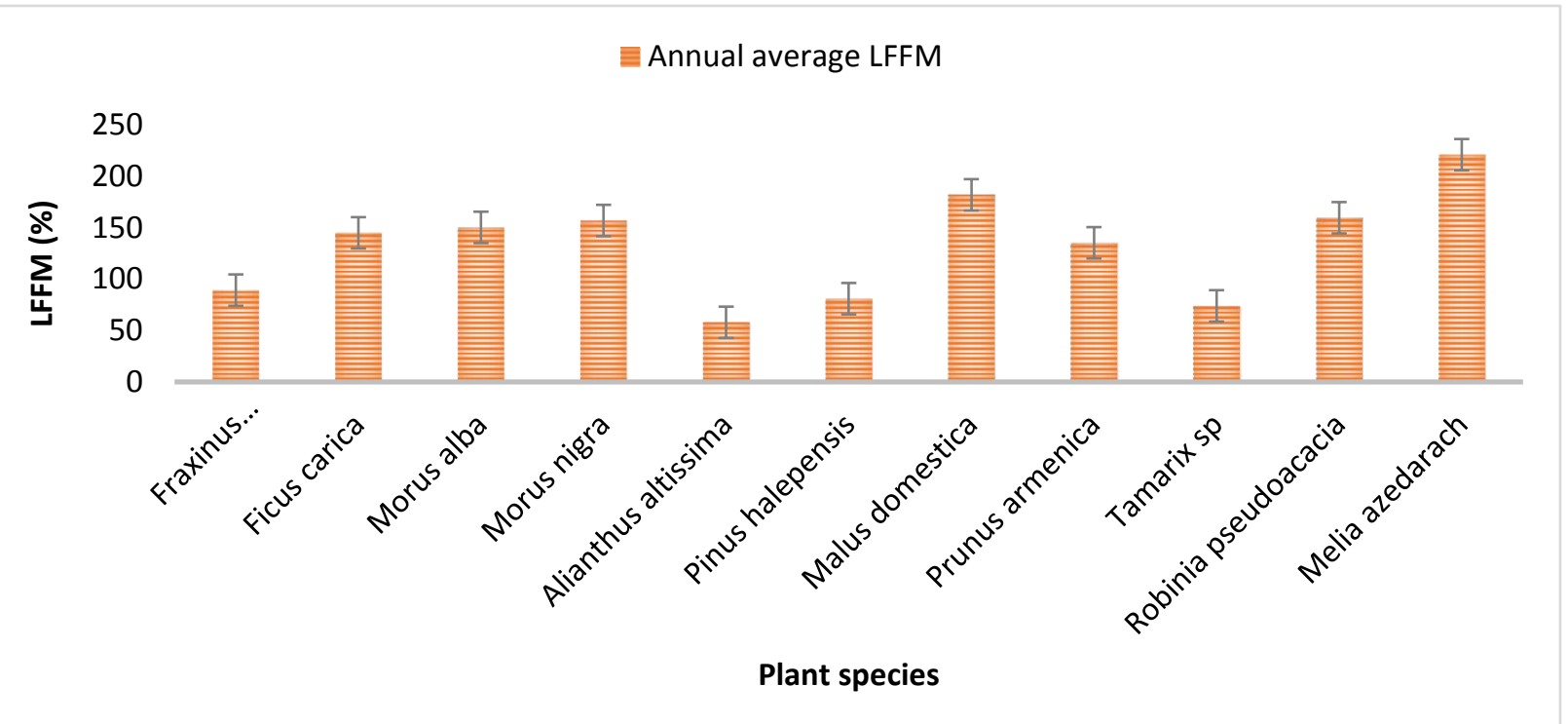

Figure 4. Annual average LFFM in different 11 woody plant species of Quetta Balochistan

Table 3. Live Fine Fuel Moisture (LFFM) (\%) in 11 different woody plant species of Quetta Balochistan

\begin{tabular}{|c|c|c|c|c|}
\hline \multirow{2}{*}{ Plant Species } & \multicolumn{3}{|c|}{ LFFM } & \multirow{2}{*}{$\begin{array}{c}\text { Statistical } \\
\text { variation }\end{array}$} \\
\hline & Spring & Summer & Autumn & \\
\hline Fraxinus xanthoxyloides & 55 & 97 & 116 & $* * *$ \\
\hline Ficus carica & 115 & 124 & 196 & $* *$ \\
\hline Morus alba & 127 & 137 & 187 & $*$ \\
\hline Morus nigra & 132 & 156 & 183 & $* *$ \\
\hline Ailanthus altissima & 47 & 57 & 68 & $*$ \\
\hline Pinus halepensis & 62 & 66 & 115 & $* * *$ \\
\hline Malus domestica & 147 & 164 & 235 & $* * *$ \\
\hline Prunus armeniaca & 112 & 122 & 172 & $* * *$ \\
\hline Tamarix sp & 56 & 59 & 109 & $* *$ \\
\hline Robinia pseudoacacia & 133 & 148 & 198 & $* * *$ \\
\hline Melia azedarach & 189 & 218 & 256 & $* * *$ \\
\hline$P$ value & 0.000 & 0.000 & 0.000 & \\
\hline
\end{tabular}

Each mean value is the replicate of five readings, $\pm=$ standard deviation $*=$ slightly significant, $* *=$ significant, $* * *$ $=$ highly significant and $\mathrm{Ns}=$ non-significant

\section{Conclusion}

This investigation concluded that RWC, LDMC and LFFMC are the best way to determine the resources use strategies of woody plants. In addition to that the leaf dry matter content and live fine fuel moisture contents are also an important parameters in fire performance forecasting in plants. Results revealed that the different plant species growing in same ecological condition showed variations in their resource-use strategies. Further that the variation in leaf RWC, leaf DMC and leaf LFFMC were also noted among the seasons. Eventually, these consequences proposed that even though investigation have exposed connections among LFFMC and arid climatic conditions, the reasons of the real variations in noticed LFFMC are extra multifaceted. Upcoming effort must emphasis on independently amplification the issues that drive periodic deviations in actual leaf water contents and dry matter contents to improve evaluate the causes for differences in live fine fuel moisture contents. 


\section{Authors' contributions}

Conceived and designed the experiment: M Jaffar \& SK Leghari, Performed the experiment: M Jaffar \& SK Leghari, Analyzed the data: M Jaffar \& SK Leghari, Contributed materials/ analysis/ tools: M Jaffar, MAK Panazai \& MI Khattak. Wrote the paper: M Jaffar \& SK Leghari.

\section{References}

1. Leghari SK, Zaidi MA \& Sarangzai AM (2013). Seasonal Variation In Leaf Relative Water, Dry Matter And Live Fine Fuel Moisture Contents In Some Common Plant Species Of Quetta, Balochistan. Fuuast $J$ Biol 3(2): 73-76.

2. Larcher W (1995). Physiological plant ecology 3rd edn (Springer, Berlin).

3. Teulat B, Monneveux P, Wery J, Borries C, Sourys I, Charrier A \& This D (1997). Relationships between relative water content and growth parameters under water stress in barley: a QTL study. New Phytol 137(1): 99107.

4. Penuela J, Munne-Bosch S, Llusia J \& Filella I (2004). Leaf reflectance and photoand antioxidant protection in field grown summer -stressed Phillyrea angustifolia. Optical signals of oxidative stress. New Phytol 162: 115-124.

5. Ogunkunle CO, Suleiman LB, Oyedeji S, Awotoye OO and Fatoba PO (2015). Assessing the air pollution tolerance index and anticipated performance index of some tree species for biomonitoring environmental health. Agroforestry Sys 89: 447-454.

6. Garnier E, Shipley B, Roumet C \& Laurent $\mathrm{G}$ (2001a). A standardized protocol for the determination of specific leaf area and leaf dry matter content. Funct Ecol 15: 688-695.

7. Grime JP, Thompson K, Hunt R, Hodgson JG, Cornelissen JH \& Rorison IH (1997). Integrated screening validates primary axes of specialization in plants. Oikos 79: 259281.

8. Poorter H \& Garnier E (1999). Ecological significance of inherent variation in relative growth rate and its components. In Pugnaire FI and Valladars F (Eds). Handbook of Funct plant ecology. Marcel Derker, New York pp 81-120.
9. Ryser P \& Urbas P (2000). Ecological significance of leaf life span among central Europian grass species. Oikos 91: 41-50.

10. Garnier E, Laurent G, Bellmann A, Debain S, Berthelier P \& Ducout B (2001b). Consistency of species ranking based on functional leaf traits. New Phytol 152: 69-83.

11. Andrews PL \& Bevins CD (2003). Behave Plus fire modeling system, version 2.0: overview. Proceedings of the Second International Wildland Fire Ecology and Fire Management Congress and Fifth Symposium on Fire and Forest Meteorology. Orlando, FL: American Meteorol Soc P5.11.

12. Pinol J, Beven K \& Viegas D (2005). Modelling the effect of fire-exclusion and prescribed fire on wildfire size in Mediterranean ecosystems. Ecolog Modelling 183: 397-409.

13. Chandler C, Cheney P, Thomas P, Trabaud L \& Williams D (1983). Fire in forestry. Vol. 1. Forest fire behaviour and effects. New York Wiley.

14. Munne- Bosh S and Penuelas J (2004). Drought- induced oxidative stress in strawberry tree (Arbutus unedo L.) growing in Mediterranean field conditions. Plant Sci 166: 1105-1110.

15. Espilta JM (1996). La regenaracio de bassos $\mathrm{d}$;alzina (Quorums ilex $\mathrm{L}$ ) pipe blanks (Pinus helepensis Mill): estudi experimental de la resposta de less plantules a la intensitat de llum I a la disponibilitat d'aigua $\mathrm{PhD}$ Thesis ; Autonomous University of Barcelonna, spain.

16. Paula S \& Pausas JG (2006). Leaf traits and resprouting ability in the Mediterranean basin. Func Ecol 20:941-947.

17. Saura-mas S \& Lloret F (2007). Leaf and Shoot Water Content and Leaf Dry Matter Content of Mediterranean Woody Species with Different Post-fire Regenerative Strategies. Annals of Bot 99: 545-554.

18. Paulsamy S, Sivakumar R \& Latha N (2000). Evaluation of air pollution tolerant tree species in Coimbatore city. $J$ Ecol Res Biocon 1: 20-23.

19. Yi Q, Jolly WM, Dennison PE \& Kropp RC (2016). Seasonal relationships between foliar moisture content, heat content and biochemistry of lodgepole pine and big 
sagebrush foliage. Inter $J$ of Wildland Fire 25: 574-578.

20. Jolly WM \& Daniel MJ (2018). PyroEcophysiology: Shifting the Paradigm of Live Wildland Fuel. Res Fire 1(1): 8.

21. Cunningham SA, Summerhayes B \& Westoby M (1999). Evolutionary divergences in leaf structure and chemistry, comparing rainfall and soil nutrient gradients. Ecol Monogr 69: 569-588.

22. Poorter $\mathrm{H} \& \mathrm{De}$ jong $\mathrm{R}$ (1999). A comparison of specific leaf area, chemical composition and leaf construction costs of field plants from 15 habitats differing in productivity. New Phytol 143: 163-176.

23. Viegas DX, Piñol J, Viegas MT \& Ogaya R (2001). Estimating live fine fuels moisture content using meteorologically-based indices. Inter J Wildland Fire 10: 223-240.

24. Castro FX, Tudela A \& Sebastia MT (2003). Modeling moisture content in shrubs to predict fire risk in Catalonia (Spain). Agri and Forest Meteorol 116: 49-59.

25. Dennison PE, Roberts DA, Thorgusen SR, Regebrugge JC, Weise D \& Lee C (2003). Modeling seasonal change in live fuel moisture and equivalent water thickness using a cumulative water balance index. Remote sensing of Environment 88: 442452.

26. Dimitrakopoulos AP \& Bemmerzouk AM (2003). Predicting live herbaceous moisture content from a seasonal drought index. Inter J of Biometeorol 47: 73-79.

27. Pellizzaro G, Cesaraccio C, Duce P, Ventura A \& Zara P (2007b). Relationships between seasonal patterns of live fuel moisture and meteorological drought indices for Mediterranean shrudland species. Inter $J$ of Wildland Fire 16: 232-241.

28. Nelson RM (2001). Water relations of forest fuels. In Forest Fire: Behaviour and ecological effects. Eds EA Johnson, K Miyanish). Academic Press London pp. 79149.

29. Running SW (1980). Environmental and physiological control of water flux through Pinus contorta. Canadian $J$ of Forest Res 10: 82-91.

30. Nelson RM (2000). Prediction of diurnal change in 10-h fuel stick moisture content. Can J For Res 30: 1071-1087.

31. Viney NR (1991). A review of fine fuel moisture modelling. International journal of eild lamd fore 1: 215-234.

32. Bertin N, Tchamitchian $\mathrm{M}$, Baldet $\mathrm{P}$, Devaux C, Brunel B \& Gary C (1999). Contribution of carbohydrate pools to the variations in leaf mass per area within a tomato plant. New Phytol 143: 53-61.

33. Woodruff DR, Meinzer FC, Marias DE, Sevanto S, Jenkins MW \& McDowell NG (2015). Linking nonstructural carbohydrate dynamics to gas exchange and leaf hydraulic behavior in Pinus edulis and juniperus monosperma. New Phytol 206: 411-421.

34. Jolly WM, Hadlow AM \& Huguet K (2014). De-coupling seasonal changes in water content and dry matter to predict live conifer foliar moisture content. Int $J$ Wildland Fire 23: 480-489.

35. Jolly WM, Hintz J, Linn RL, Kropp RC, Conrad ET, Parsons RA \& Winterkamp J (2016). Seasonal variations in red pine (Pinus resinosa) and jack pine (Pinus banksiana) foliar physio-chemistry and their potential influence on stand-scale wildland fire behavior. For Ecol Manag 373: 167178.

36. Wever LA, Flanagan LB \& Carlson PJ (2002). Seasonal and interannual variation in evapotranspiration, energy balance and surface conductance in a northern temperate grassland. Agric For Meteorol 112: 31-49. 